\title{
INSTRUMENTOS E TÉCNICAS PARA INVESTIGAÇÃO EM ENFERMAGEM PSIQUIÁTRICA
}

\author{
Maria Aparecida Minzoni *
}

MINZONI, M. A. Instrumentos e técnicas para investigação em enfermagem psiquiátrica. Rev. Esc. Enf. USP, São Paulo, 14(2):185-188, 1980.

Nossa situação de docente da Escola de Enfermagem, sem campo de estágio definido ${ }^{1}$ para os estudantes de enfermagem psiquiátrica, fez-nos conviver com pessoal de enfermagem em diversos hospitais de pesquiatria, sentir de perto suas dificul. dades e deficiências e cuidar de doentes mentais, internados em instituições que se orientavam por diferentes políticas de tratamento e assistenciais. Com isso, ganhamos experiência e vivência que foram utilizadas em nossas atividades de pesquisa, sobretudo na construção de instrumentos para investigação (MINZONI, 1971 e 1975).

Atualmente, em nosso trabalho como docente e orientadora de alunos do curso de pós-graduação, na área de enfermagem psiquiátrica, temos observado as dificuldades dos mestrandos em definir os instrumentos para investigação, porquanto falta-lhes modelos e padrões nos quais possam basear-se. Os trabalhos nacionais, nessa área, são encontrados quase exclusivamente, nas teses de mestrado ou para concurso na carreira docente, as quais, geralmente, são pouco difundidas.

As pesquisas em enfermagem psiquiátrica, de modo geral, seguem os modelos usados em ciências sociais e os dados qualitativos trazem maiores informações e são mais úteis do que os dados quantitativos, sobretudo, se o enfoque estiver voltado para uma linha psiquiátrica mais dinâmica.

Temas para investigação que envolvem estudos das atitudes do pessoal de enfermagem que sejam terapêticas; funções do enfermeiro; conceitos sobre doente mental; interferência do contexto e do nivel sócio-econômico-sanitário do pessoal de enfermagem, na assistência ao paciente internado; possibilidades e tentativas de mudança na assistência de enfermagem e suas conseqüências, têm sido pouco explorados ou ainda não foram estudados.

$\mathrm{E}$, questōes como: "o cuidado de enfermagem que se tem oferecido aos doentes mentais é adequado?" - “como o paciente internado percebe o ambiente hospitalar?" - "Por que o pessoal de enfermagem modifica suas atitudes para com os pacientes psiquiátricos, após alguns anos de serviço?", continuam esperando uma resposta.

Considerando o que foi exposto e sentindo a necessidade de incentivar a pesquisa em enfermagem psiquiátrica, pensamos em apresentar alguns instrumentos

- Professor Adjunto do Departamento de Enfermagem Psiquiátrica e Ciências Humanas da Escola de Enfermagem de Ribeirãa Preto - USP.

1 Os estudantes fazem estágios de enfermagem psiquiátrica em hospitais particulares e em um hospital governamental, onde a maioria dos pacientes é crônico, de muitos anos. 
para investigação, com o objetivo de colaborar com aqueles que desejam fazer pesquisa, nessa área. Os instrumentos apresentados foram utilizados por nós e outros enfermeiros psiquiátricos e têm sido usados por alunos de pós-graduação, em planos de pesquisa, para dissertação de mestrado.

$\mathrm{Na}$ apresentação desse material não nos limitamos a transcrever os instrumentos; são descritos, também, o preparo do material, a técnica de coleta dos dados e sua tabulação, conforme cada caso.

A seguir encontra-se um resumo do conteúdo, e os objetivos do material. Este será dividido em duas partes que serão desenvolvidas nos números subseqüentes desta Revista.

\section{I - CLASSIFICAÇÃO DAS ATIVIDADES EXECUTADAS POR PESSOAL DE ENFERMAGEM PSIQUIÁTRICA}

Consta de uma lista de atividades possíveis de serem executadas pelo pessoal de enfermagem, no cuidado ao doente mental internado. Tem como objetivo conhecer o que o pessoal de enferemagem está fazendo, ao ministrar cuidados a pacientes internados em hospital psiquiátrico.

Seu conteúdo inclui:

\section{INTRODUÇÃO}

\section{TÉCNICA DE OBSERVAÇÃO}
1.1 Definição de termos
1.2 Passos da observação
1.3 Registro das observações
1.4 Pessoal de enfermagem, segundo o nível
1.5 Escala de horário

2. LISTA DAS ATIVIDADES DO PESSOAL DE ENFERMAGEM, COM SUAS AREAS E AS CLASSIFICAÇôES (Modelo)
2.1 Área básica
2.2 Area de tratamento
2.3 Área de comunicação
2.4 Área de inter-relacionamento
2.5 Área administrativa
2.6 Área doméstica
2.7 Área de ausências 


\section{REFERÊNCIAS BIBLIOGRÁFICAS}

\section{II - INVENTÁRIO DE SITUAÇÕES PARA PESQUISA EM ENFERMAGEM PSIQUIÁTRICA}

Consta de uma relação de 138 situações que podem ocorrer com pacientes internados em hospitais psiquiátricos e as atitudes possiveis que o pessoal de enfermagem deve tomar, na situação.

Seu objetivo é levantar dados sobre o conhecimento do pessoal de enfermagem, em relação aos cuidados do paciente internado, quanto às suas necessidades básicas, às terapias somáticas e aos sinais e sintomas. Serve, também, para avaliar como o pessoal de enfermagem está agindo ao cuidar do paciente.

Encontra-se como conteúdo os seguintes itens:

\section{INTRODUÇÃO}

1. APLICAÇÃO DO INVENTÁRIO DE SITUAÇõES

2. DEFINIÇÕES DE TERMOS

3. CLASSIFICAÇÃO DAS RESPOSTAS

3.1 Avaliação das respostas adequadas, incompletas e inadequadas

4. PROCEDIMENTO-PADRÃO PARA O INVENTÁRIO DE SITUAÇÕES

5. REFERENCIAS BIBLIOGRÁFICAS

\section{III - RELAÇÃO DE ATITUDES DO PESSOAL DE ENFERMAGEM PSI- QUIATRICA E TESTE DE PERCEPÇÃO DE FUNÇÕES}

Esse material surgiu a partir da necessidade de se verificar se o pessoal de enfermagem usava, na prática, os conhecimentos adquiridos em aulas teóricas.

0 primeiro consta de uma relação de atitudes que o pessoal de enfermagem pode tomar, com pacientes internados, em hospitais psiquiátricos. Essas atitudes podem ser positivas ou negativas.

0 segundo refere-se às atividades que são executadas no cuidado ao doente mental e como o pessoal as percebe, segundo as consideram importantes, gosta de executá-las e as executa.

Seus objetivos são, respectivamente: 199) avaliar as atitudes (custodiais ou terapêuticas) que o pessoal teria, com o doente mental, ao assisti-lo; $2 .^{\circ}$ ) estudar o que o pessoal de enfermagem está fazendo; se valoriza suas atividades e se executa o que acha que é importante e o que gosta, a partir da percepção de si mesmo, como profissional. 
O conteúdo desse material compreende:

\section{INTRODUÇÃO}

\section{RELAÇÃO DE ATITUDES}

1.1 Técnica de observação

1.2 Critérios de inclusão nas áreas

1.3 Critérios para classificação, segundo o tipo de atitude

MODELO DE LISTA DE ATITUDES COM A CLASSIFICAÇÃO POR AREA E POR TIPO

2. TESTE DE PERCEPÇÃO DE FUNÇÕES
2.1 Preparo do material
2.2 Aplicação do teste

MODELO DO TESTE DE PERCEPÇÃO DE FUNÇÕES

\section{TABULAÇÃO \\ 4. REFERENCIAS BIBLIOGRÁFICAS}

\section{REFERENCIAS BIBLIOGRAFICAS}

MINZONI, M. A. Assisténcia de enfermagem psiquiátrica: estudo da situação num municipio paulista. Ribeirão Preto, 1971. (Tese de Doutoramento - Escola de Enfermagem de Ribeirão Preto da USP). MINZONI, M. A. Assisténcia ao doente mental internado: ańlíse de uma experiência de treinamento de atendentes em hospital psiquiátrico. Ribeirão Preto, 1975. (Tese de Livre Docência - Escola de Enfermagem de Ribeirão Preto da USP). 